\title{
Social prognosis in patients with ulcerative colitis
}

\author{
C HENDRIKSEN， V BINDER
}

\section{Summary and conclusions}

One hundred and twenty-two randomly selected patients with ulcerative colitis ( 28 of whom had undergone colectomy) were interviewed to obtain data on the quality of their family, emotional, social, and professional lives. They were compared with an age- and sex-matched group of patients with acute conditions from the same area.

The two groups were similar in marital status, the frequency of severe family or sexual problems, leisure activities, physical and earning capacity, the incidence of mental disorders before the interview, and intake of alcohol and psychopharmacological drugs. A higher proportion of the patients with colitis had had a higher education and belonged to higher socioeconomic groups than the controls, and this difference had been present at the time of diagnosis.

These results show that patients with ulcerative colitis seem to adapt themselves well to their condition and suffer few social or professional disabilities.

\section{Introduction}

In a previous study ${ }^{1}$ we showed a far better prognosis in ulcerative colitis than had hitherto been assumed. Thus women with the disease had no excess mortality when compared with the general population, while in men the one-year mortality showed an increase of $3.5^{\circ} \%$ but only among those aged over 60 years at the onset of the disease. We concluded that the improved prognosis was due mainly to a high rate of surgery, about $20 \%$ of the patients having had a colectomy within the first 10 years of the disease.

With its highest incidence among 15 to 35 year olds, ulcerative colitis tends to affect patients during their most active years. We therefore performed a survey to determine the extent to which they could live a normal life from a family, social, and professional point of view to supplement information on prognosis with an evaluation of the quality of life.

\section{Patients and methods}

From among the patients with ulcerative colitis attending the medical gastroenterology department at Herlev Hospital, University of Copenhagen, we randomly selected 123 for interview. The diagnosis of ulcerative colitis was based on case history, sigmoidoscopy, cytology or histology, and radiographs of the colon, and at least three out of four diagnostic criteria had to be fulfilled. ${ }^{2: 3}$ Patients with specific infectious and neoplastic diseases of the colon were excluded. The patients selected for interview had to have had their disease for longer than a year, be aged over 17 years, and have dates of birth in January, February, April, July, or October. One patient refused to participate. The other 122 gave their informed consent, as did the 83 controls. The controls were an age- and sex-matched group of patients admitted to the acute wards of the hospital for acute abdominal pain, deep venous thrombosis, pneumonia, abscesses, etc. Patients with chronic conditions were excluded.

Medical-gastroenterological Department C, Herlev Hospital University of Copenhagen, 2730 Herlev, Copenhagen, Denmark C HENDRIKSEN, CANDMED, registrar $\mathrm{V}$ BINDER, MD, consultant physician
Data were collected by a questionnaire on professional, emotional and family conditions filled in at an interview with $\mathrm{CH}$. The interview was always in private and lasted about 25 minutes.

The patients were grouped in five socioeconomic groups as defined by the Danish National Institute of Social Research ${ }^{4}:$ I-self-employed in large enterprises and salaried employees at top levels; II-selfemployed in medium-sized enterprises and salaried employees at upper levels; III-other self-employed workers in non-agricultural enterprises, most freeholders, and salaried employees at medium levels; IV-smallholders, salaried employees at lower levels, and skilled manual workers; V-unskilled and semi-skilled manual workers. Married women without paid work were grouped according to their husband's professional status, married women with paid work according to their own status, and unemployed and retired people according to their most recent status.

The $\%^{2}$-test was used as significance test (when not otherwise stated) with a significance level of $5 \%$.

\section{Results}

The 122 patients with ulcerative colitis (70 women and $52 \mathrm{men}$ ) had a median age of 44 years (range $20-82$ years) and a median duration of the disease of 10 years (range 1-53 years). The 47 women and 36 men in the control group had a median age of 44 years (range 21 to 79 years) and a duration of disease of less than 14 days.

Twenty-eight patients with colitis had undergone colectomy; in 25 it had been combined with ileostomy and in three with ileoproctostomy. Among the patients who had not undergone operation the disease was chronic continuous in 21 patients and chronic intermittent in 73 .

\section{FAMILY AND SOCIAL CONDITIONS}

Table I shows that most patients in both groups were married or lived under conditions similar to marriage. Other types of marital status were evenly distributed in both groups. The patients with ulcerative colitis had fewer children than the controls (Mann Whitney rank sum test: $t=2 \cdot 7, \mathrm{p}<0.05$ ), but the difference was small (with a median of 2 in both groups) and present only in women.

Three-quarters of the patients said they had regular sexual activity $(89(73 \%)$ of those with colitis and $64(77 \%)$ controls $)$. Sexual problems were admitted by 15 patients with colitis and nine controls (table II). Only $12\left(10^{\circ}\right)$ with colitis group and six $(7 \%)$ controls

TABLE I-Family relations and mental and social health

\begin{tabular}{lccccc}
\hline & Married & $\begin{array}{c}\text { Median No } \\
\text { of children }\end{array}$ & $\begin{array}{c}\text { Sexual } \\
\text { problems }\end{array}$ & $\begin{array}{c}\text { Severe } \\
\text { family } \\
\text { problems }\end{array}$ & $\begin{array}{c}\text { Previous } \\
\text { treatment } \\
\text { for mental } \\
\text { disorders }\end{array}$ \\
\hline $\begin{array}{c}\text { Patients } \\
(\mathrm{n}=122) \\
\begin{array}{c}\text { ontrols } \\
(\mathrm{n}=83)\end{array}\end{array}$ & $100(82)$ & 2 (range 0-5) & $15(12)$ & $20(16)$ & $16(13)$ \\
\hline
\end{tabular}

TABLE II-Type of sexual problems in the groups of patients

\begin{tabular}{lcc}
\hline & Women & Men \\
\hline $\begin{array}{c}\text { Patients with colitis: } \\
\text { No colectomy }(\mathrm{n}=10)\end{array}$ & $\begin{array}{c}\text { Reduced libido (6), } \\
\text { fistula (1) } \\
\text { Reduced libido (1), } \\
\text { abscess (1), emotional } \\
\text { disturbance (1) } \\
\text { Reduced libido (2), } \\
\text { emotional disturbance } \\
\text { Controls }(\mathrm{n}=9)\end{array}$ & $\begin{array}{c}\text { Reduced libido (2), } \\
\text { emotional disturbance } \\
\text { (1) } \\
\text { Erectile impotence (1), } \\
\text { emotional } \\
\text { disturbance (1) } \\
\text { Erectile impotence (2) }\end{array}$ \\
\hline
\end{tabular}


complained of loneliness, and there were few with marital problems (table I).

To elucidate the alleged relationship between emotional strain and ulcerative colitis all patients in the two groups were questioned about previous psychiatric examinations or treatment. Only 16 patients with colitis and 14 controls admitted to having treatment (table 1), and daily consumption of alcohol and psychopharmacological drugs was equal in the two groups.

Data on social activity were collected through questions about participation in sport events, cultural activities, and courses, membership of associations and clubs, frequency of contact with friends, and travelling frequency. By use of a scoring system the degree of social activity was classified as high, moderate, or low. Table III shows that there was no difference between patients with colitis and the controls. The level of physical activity was similarly determined on the basis of athletic participation, daily exercise, and capacity of bodily movement. Again the two groups did not differ (table III).

TABLE III-Degree of social and physical activity in both groups

\begin{tabular}{|c|c|c|c|c|c|c|}
\hline & \multicolumn{3}{|c|}{ Social activities } & \multicolumn{3}{|c|}{ Physical activities } \\
\hline & High & Moderate & Low & High & Moderate & Low \\
\hline $\begin{array}{l}\text { Patients with } \\
\text { colitis }(n=122) \\
\text { Controls }(n=83)\end{array}$ & $\begin{array}{l}45(37) \\
25(30)\end{array}$ & $\begin{array}{l}57(47) \\
40(48)\end{array}$ & $\begin{array}{l}20(16) \\
18(22)\end{array}$ & $\begin{array}{l}42(34) \\
27(33)\end{array}$ & $\begin{array}{l}71(58) \\
51(61)\end{array}$ & $\begin{array}{l}9(7) \\
5(6)\end{array}$ \\
\hline
\end{tabular}

\section{PROFESSIONAL CONDITIONS}

There were more patients with a higher education $\left(\chi^{2}=6 \cdot 3\right.$, $\mathrm{p}<0.05)$ and fewer totally unskilled workers $\left(\chi^{2}=3.5, p<0.05\right)$ in the colitis group than in the control group (table IV). The rate of employment was high and similar in both groups (table V). Few patients were unemployed or sick, and $102(84 \%)$ with colitis and 71 $(86 \%)$ controls claimed full working capacity. Three patients received disablement pension because of their intestinal disease.

Sixty-one controls $(73 \%)$ and 84 patients with colitis $(69 \%)$ said that they had had fewer than 11 days of absence from work during the year before the interview-an insignificant difference. Similarly, there was no difference in the frequency of change of work during the last five years.

Among the patients in employment, $92^{\circ}$ in the colitis group and $97 \%$ in the control group said that their health did not restrict their work. Also, there was no difference between the two groups in the number of patients with physically or emotionally straining working conditions $-40 \%$ among the patients with colitis and $44 \%$ among the controls. The annual gross income was identical in the two groups.

Table VI shows that significantly more patients with colitis belonged to the highest socioeconomic group $\left(\chi^{2}=8.5 ; p<0.05\right)$. The difference was smaller, though still significant, when the social status at the time of diagnosis was compared. From the onset of disease to the time of the study the social status of the patients with colitis improved significantly. The socioeconomic pattern in the control group did not

TABLE IV-Level of education in the two groups

\begin{tabular}{|c|c|c|c|c|c|}
\hline & $\begin{array}{c}\text { University } \\
\text { degree }\end{array}$ & $\begin{array}{c}\text { Theoretical } \\
\text { non-university } \\
\text { education }\end{array}$ & $\begin{array}{l}\text { Skilled } \\
\text { worker }\end{array}$ & $\begin{array}{c}\text { Semi-skilled } \\
\text { worker }\end{array}$ & $\begin{array}{l}\text { Unskilled } \\
\text { worker }\end{array}$ \\
\hline $\begin{array}{l}\text { Patients with } \\
\text { colitis }(n=122) \\
\text { Controls }(n=83)\end{array}$ & $\begin{array}{r}15(12) \\
2(2)\end{array}$ & $\begin{array}{l}18(15) \\
12(15)\end{array}$ & $\begin{array}{l}50(41) \\
30(36)\end{array}$ & $\begin{array}{l}11(9) \\
10(12)\end{array}$ & $\begin{array}{l}28(23) \\
29(35)\end{array}$ \\
\hline
\end{tabular}

TABLE V-Employment in the two groups

\begin{tabular}{lllllll}
\hline \multicolumn{1}{c}{$\begin{array}{c}\text { Fully } \\
\text { employed }\end{array}$} & Unemployed Housewife & Student & Disabled & Pensioner \\
\hline $\begin{array}{c}\text { Patients with } \\
\text { colitis } \\
(n=122) \\
\begin{array}{c}\text { Controls } \\
(n=83)\end{array}\end{array}$ & $86(71)$ & $3(2)$ & $10(8)$ & $4(3)$ & $2(2)$ & $17(14)$ \\
\hline
\end{tabular}

TABLE VI-Socioeconomic status of the patients in both groups

\begin{tabular}{|c|c|c|c|c|c|c|}
\hline & Group: & I & II & III & IV & $\mathrm{V}$ \\
\hline $\begin{array}{l}\text { Patients with colitis } \\
(\mathrm{n}=122) \ldots\end{array}$ & $\cdots$ & $18(15)$ & $19(15)$ & $13(11)$ & $50(41)$ & $22(18)$ \\
\hline
\end{tabular}

differ from that for the population aged 20 to 69 years in the County of Copenhagen and in Denmark in 1976.

To determine whether a difference in the degree of use of medical services might explain this uneven social distribution, the patients with colitis in socioeconomic groups $\mathrm{I}$ and $\mathrm{V}$ who had not undergone operation were compared with respect to activity of the disease. Those in group I had a higher activity, which ruled out the possibility of a threshold phenomenon.

Patients with ulcerative colitis were asked whether they had been exposed to severe emotional strain-for example, serious diseases or deaths in close relatives or friends or serious marital, professional, or economic problems-within the three months before the onset of their disease. Similar proportions of both groups had been under such stress $\left(35\left(29^{\circ}{ }_{0}\right)\right.$ patients with colitis and $21\left(25^{\circ} \%\right)$ controls).

\section{Discussion}

Our results sustain the clinical impression that patients with ulcerative colitis manage well socially despite their disease. Family, social, and professional conditions were similar for patients with colitis and for age- and sex-matched patients living in the same region.

The patients with colitis had a higher educational status than the controls and, consequently, more of them belonged to the highest socioeconomic group. This agrees with the findings of Bonnevie, ${ }^{5}$ who showed that in two socioeconomic groups the educational and social levels were higher among patients with colitis than in the general population. In a controlled survey similar to ours Samuelsson ${ }^{6}$ showed that though the socioeconomic pattern was similar in a group of patients with ulcerative colitis and controls from the same region (Uppsala), the general level was higher than that for the rest of the Swedish population. Monk et $a l^{7}{ }^{7}$ however, found no difference in professional status between patients from Baltimore with colitis and the general population. But their survey is not comparable with ours because of the differences in the organisation of health care in Denmark and the United States and because of the ethnic composition of the patient population.

The reason for the higher socioeconomic status of patients with colitis is not clear. Our results do not support the theory that people whose disease activity is low and who belong to the lowest socioeconomic groups are less inclined to consult a doctor than people belonging to the highest group. Nor do they support the suggestion that people in whom a chronic intestinal disease is diagnosed become more motivated to obtain a theoretical education and thus move to a higher social status. The socioeconomic status was lower in our controls at the time of the interview than in our patients with colitis at the time of the diagnosis.

Previous surveys ${ }^{8-10}$ have shown that patients with ulcerative colitis more often have close relatives suffering from intestinal diseases than has the general population. Our findings agree with the hypothesis of a genetic correlation between intelligence and a predisposition to inflammatory intestinal diseases, but we cannot exclude the possibility that the frequency of external factors important to the pathogenesis increases with socioeconomic status.

Patients with ulcerative colitis had not experienced greater emotional strain before the onset of disease than had other patients. As the two groups had similar consumptions of alcohol and psychopharmacological drugs and a similar incidence of mental disorder, ulcerative colitis does not seem to be determined by a primary mental abnormality. 
Out of 84 patients with colitis who received only medical treatment at St Mark's Hospital, London, ${ }^{11}$ a quarter had reduced social and leisure capacity and 15 reduced earning capacity. The lack of a control group makes it impossible to explain the apparent discrepancy from our results, but the percentage of seriously ill patients was higher at St Mark's.

The active attitude to surgery in our department, which considers a bad "quality of life" as an indication for surgery, has naturally influenced our results. We have no wish to minimise the inconvenience of this serious disease, but with optimal treatment, whether medical or surgical, patients with ulcerative colitis seem to adapt themselves very well to their chronic disease.

\section{References}

${ }^{1}$ Bonnevie O, Binder V, Anthonisen P, Riis P. The prognosis of ulcerative colitis. Scand 7 Gastroent 1974;9:81-91.

2 Anthonisen P, Riis P. Eosinophilic granulocytes in the rectal mucus of patients with ulcerative colitis and Crohn's disease of the ileum and colon. Scand 7 Gastroent 1971;6:731-4.

${ }^{3}$ Riis $\mathrm{P}$, Anthonisen $\mathrm{P}$. The differential diagnosis between ulcerative colitis and Crohn's disease of the colon. Gregor O, Riedl O, eds. 8th International Congress of Gastroenterology, Prague, 1968. Stuttgart, New York: Fk Schattauer Vertag, 1969: 912-3.

${ }^{4}$ Hansen EJ. The distribution of living conditions. Part I. Copenhagen: Danish National Institute of Social Research, 1978. (Publication 82.)

${ }^{5}$ Ronnevie O. A socio-economic study of patients with ulcerative colitis. Scand $\mathcal{F}$ Gastroent 1967;2:129-36.

6 Samuelsson S-M. Ulcerös kolit ock proktit. Uppsala, Socialmedicinska Institutionen, Uppsala Universitet, 1976.

7 Monk M, Mendeloff AI, Siegel CI, Lilienfeld A. An epidemiological study of ulcerative colitis and regional enteritis among adults in Baltimore. II. Social and demographic factors. Gastroenterology 1969; $56: 847-57$.

${ }^{8}$ Binder V, Weeke E, Olsen JH, Anthonisen P, Riis P. A genetic study of ulcerative colitis. Scand $\mathcal{F}$ Gastroent 1966;1:49-56.

9 Lewkonia RM, McConnell RB. Familial inflammatory bowel diseaseheredity or environment ? Gut 1976;17:235-43.

${ }^{10}$ Kirsner JB. Genetic aspects of inflammatory bowel disease. Clinics in Gastroenterology 1973;2:557-75.

${ }^{11}$ Mallett SJ, Lennard-Jones JE, Bingley J, Gilon E. Colitis. Lancet 1978; ii :619-21.

(Accepted 24 June 1980)

\title{
Increased incidence of faecal Klebsiella pneumoniae in patients with HLA B7 CREG antigen and men with rheumatoid arthritis
}

\author{
ROLAND EBRINGER， DIANE COLTHORPE, ADAM YOUNG, MARY CORBETT
}

\section{Summary and conclusions}

In a study of the carriage of faecal Klebsiella pneumoniae in 106 patients with rheumatoid arthritis the incidence of carriage was higher in men $(28 \%)$ than women $(14 \%)$ $(p<0.001)$ and klebsiellae were isolated on two or more occasions from a higher proportion of men than women $(p<0.002)$. The incidence of carriage was increased among patients with rheumatoid arthritis who had $B 7$ cross-reacting (B7 CREG) antigens (32\% v $13 \%$ $\mathrm{p}<0.001)$. Carriage of klebsiellae was not associated with clinical disease activity, raised erythrocyte sedimentation rate, drug treatment, or the presence of HLA Dw4 or DRw4 or both.

Thus the carriage and prevalence of faecal Klebsiella pneumoniae appear to be partly determined by the sex and HLA state of the host.

\section{Introduction}

Evidence exists of cross-reactivity between antigens of the Gram-negative bacillus Klebsiella pneumoniae and lymphocytes positive for HLA B27 in ankylosing spondylitis. ${ }^{1-3}$ We showed that patients with active disease ${ }^{4}$ and acute anterior uveitis in ankylosing spondylitis ${ }^{5}$ have a higher incidence of faecal carriage of klebsiellae than controls or patients with inactive disease. Other investigators confirmed that carriage of faecal $\mathrm{Kl}$ aerogenes

\footnotetext{
Department of Rheumatology, Middlesex Hospital, London W1P 9PG

ROLAND EBRINGER, MRCP, Matilda Poole clinical fellow DIANE COLTHORPE, FIMLS, medical laboratory scientist ADAM YOUNG, MRCP, senior registrar

MARY CORBETT, FRCP, consultant rheumatologist
}

is strongly associated with acute anterior uveitis and peripheral synovitis in ankylosing spondylitis. ${ }^{6}$ Another group was unable to confirm these findings. ${ }^{7}$ Raised erythrocyte sedimentation rates, concentrations of C-reactive protein, and pain scores and increased consumption of anti-inflammatory drugs are also all independently associated with more active disease and with increased incidence of klebsiellae in faecal cultures (unpublished observations). ${ }^{8}$

These findings led to the hypothesis that klebsiella infection may lead to episodes or exacerbations of spinal, peripheral joint, or ocular inflammation in patients with ankylosing spondylitis. An alternative explanation is that the differences in incidence are the result of inflammatory disease rather than its cause and could therefore occur in other inflammatory rheumatic conditions such as rheumatoid arthritis, or that anti-inflammatory drugs may change the incidence of carriage of klebsiella. To examine these possibilities we followed up over three years a group of patients with rheumatoid arthritis. We aimed at determining the incidence of faecal carriage of $\mathrm{Kl}$ pneumoniae and other Gramnegative bacteria associated with postinfectious arthritis in a control population of patients with rheumatoid arthritis, and we compared these results with our reported findings in patients with ankylosing spondylitis.

\section{Patients and methods}

Patient selection-The patients were some of those in a long-term prospective study of early rheumatoid arthritis. ${ }^{9}$ Patients enter this study within the first 12 months of onset of arthritis and are initially followed up at four-monthly intervals. Most patients have definite or classical rheumatoid arthritis according to the criteria of the American Rheumatism Association. ${ }^{10}$ All patients attending the clinic were invited to participate. Sterile collection containers were posted to the patients and a fresh faecal sample collected at the time of the visit. Joint disease activity was divided into three categories and assessed as highly active, moderately active, or inactive. The assessment was 